\title{
Radiology in Epidemiological Studies and some Therapeutic Trials*
}

\author{
G. SIMON, $†$ M.D., F.R.C.P., D.M.R.E., F.F.R.
}

Brit. med. F., 1966, 2, 491-494

The use of radiology in studying the epidemiology of certain industrial pulmonary diseases, such as those produced by silica and coal, is well known, so I propose to concentrate first on radiology in therapeutic trials of drug combinations in pulmonary tuberculosis, which is still the major problem in chest disease in many parts of the world, and secondly on radiology in epidemiological studies of chronic bronchitis and emphysema and its value in the prognosis of these conditions.

In order that radiology may be of help in therapeutic trials or epidemiological surveys, it must indicate the presence or absence of a lesion with a fair degree of accuracy. This condition is fulfilled in pulmonary tuberculosis, for single-view chest radiographs have often shown at least which persons in the population are likely to be suffering from an active form of this disease or not. On the other hand, radiography would be useless to show the incidence of chronic bronchitis, since in the majority of persons who in the previous three years have had two or more periods of cough and sputum lasting for three weeks or over (M.R.C. (1965) definition of chronic bronchitis) no abnormalities appear in the radiograph.

\section{Radiological Technique}

In most epidemiological surveys or therapeutic trials only a single anterior-view radiograph is taken on each occasion. This conduces to rapidity, in the interest of the person being radiographed, and to economy, which may be to the advantage of the State or the research fund. But such a simple technique has its limitations. For instance, some tuberculous lesions, and especially neoplastic lesions, may pass undetected unless a lateral view, or even a lateral-view tomogram, is taken, while the diagnosis of emphysema may be made more certain if an additional anterior view in expiration is taken to confirm airtrapping, along with a lateral view on inspiration to show if the diaphragm is flat and the retrosternal translucent area enlarged. Thus, before using the chest radiograph as evidence, it is necessary to know roughly the risk or error of using only a single anterior view. In the case of tuberculosis the risk of error is relatively small, and in the end often immaterial to the patient, though not necessarily to contacts. Such an error is often immaterial statistically. In the case of lung cancer the statistician will learn only too soon about cases missed in an initial radiograph, and he can make the necessary corrections; but not so the patients.

More elaborate $x$-ray techniques, such as tomography for the proof or exclusion of cavities, are usually impracticable in largescale surveys, either because the necessary skill and equipment are not locally available or because the time and expense are thought to be too great to justify their use. I rather suspect that inertia is also a factor, for tomography with the multisection box technique is both rapid and easy, while its accuracy compares favourably with the more time-consuming single-cut technique.

\section{Accuracy of Radiological Diagnosis}

The radiological method is often attacked because of its inaccuracy, and much has been said about observer-error (Garland, 1950; Yerushalmy et al., 1951; Fletcher, 1964).
Distinction, however, should be made between failure of the method-that is, the radiograph failing to show the lesionand observer-error. In the former case a distinction should be made between a lesion which is invisible in a standard posterioranterior view but which can be seen by more-refined radiographic techniques and the lesion that cannot be shown by radiography at all-for example, uncomplicated chronic bronchitis. When judging observer-error, distinction must be made between failure of the observer to see a shadow and his failure to assess its significance correctly.

In judging whether a lesion is better or worse, care must be taken to see that the position of the patient is the same in both radiographs, since dissimilar positioning causes more disagreement between observers than differences of blackening due to variations in exposure.

Greater diagnostic uniformity is possible if the radiographic findings are freely discussed by the observers, or if the period of observation is extended so that improvement or deterioration may become indubitable. In this respect I prefer three months to one month for the initial assessment, and two years rather than one year for the final assessment in chemotherapy trials for tuberculosis.

Observer-error of both kinds can be greatly reduced if measurable data or even what is seen are recorded on a prescribed form. Ideally this should be only for quantitative observations, but in practice allowance may have to be made for subjective observations. The form used must be so designed that the data recorded should lead to certain conclusions, and it may be necessary to agree beforehand which data will point to a particular conclusion.

In trials of therapeutic agents in sputum-positive pulmonary tuberculosis accuracy of observation will be enhanced if, for instance, the size of the largest cavity is measured and a statement made on whether it is the only cavity or whether there are others (which can be measured); all of this information can then be recorded on a well-designed form such as that recommended by the Veterans Administration (1958) (Table I).

\section{Extract from Veterans Administration (1958). Group I. No cavity. \\ Group II. Single cavity: (A) $2 \mathrm{~cm}$. or less in diameter; (B) more than $2 \mathrm{~cm}$ and less than $4 \mathrm{~cm}$. in diameter; (C) $4 \mathrm{~cm}$. or more in diameter. \\ oup III. Multiple cavities: (A) largest cavity $2 \mathrm{~cm}$. or less in diameter (B) largest cavity more than $2 \mathrm{~cm}$. and less than $4 \mathrm{~cm}$. in diameter (C) largest cavity $4 \mathrm{~cm}$. or more in diameter. \\ 2. Add the following descriptive classificaticn: \\ 1. Hairline or thin wall. \\ 2. Cavity wall thicker than hairline but less than $0.5 \mathrm{~cm}$. in width. \\ 2. Cavity wall thicker than hairline but less \\ 4. Cavity which is "axillary or against the chest wall." \\ 5. Cavities which occur in atelectatic portions of the lung. \\ Grading: Nil, slight, moderate, extensive.}

Other data that might be of value are: (1) the thickness of the cavity wall, to find if thin-walled cavities heal better than those with thick walls ; (2) the site of the cavity, particularly whether it lies against the chest wall in the axilla or not, as this might be an adverse factor; and (3) whether the cavity lies within aerated lung, an area of consolidated lung, or in an atelectatic lobe.

* Based on the Marc Daniels Lecture given at the Royal College of Physicians of London on 12 January 1966.

† Radiologist, X-ray Diagnosis Department, St. Bartholomew's Hospital and Brompton, London. 
Table II, an analysis of a number of cases recorded and grouped in this manner in an East African investigation (Dr. J. F. Heffernan, personal communication, 1966), suggests that cavities in atelectatic lobes are slower to disappear than others. However, the disappearance of tubercle bacilli from the sputum was just as satisfactory as in the other groups, and such disappearance may occur before the wall of the cavity is completely sterilized (Eade et al., 1959). Persistence of a cavity, therefore, may indicate a longer course of treatment than if the cavity resolves, especially when ideal conditions for treatment are not available-for example, limited supply of drugs because of cost, or inability to supervise the patient over a prolonged period.

TABLE II.-East African Thiacetazone Investigation, Study K. Comparison of Results at 6 and 12 Months for Patients with Cavities Situated in Atelectatic Lung, Not Situated in Atelectatic Lung, and All Cavities

\begin{tabular}{|c|c|c|c|c|c|c|}
\hline \multirow{4}{*}{ Period } & \multirow{4}{*}{ Type of Cavitation } & \multicolumn{5}{|c|}{$\begin{array}{l}\text { Patients with Cavitation } \\
\text { at Start of Period }\end{array}$} \\
\hline & & \multirow{3}{*}{$\begin{array}{l}\text { Total } \\
\text { Assessed }\end{array}$} & \multicolumn{4}{|c|}{ Cavitation } \\
\hline & & & \multicolumn{2}{|c|}{ Gone } & \multicolumn{2}{|c|}{ Less } \\
\hline & & & No. & $\%$ & No. & $\%$ \\
\hline \multirow{3}{*}{$\begin{array}{c}0-6 \\
\text { months }\end{array}$} & \multirow{3}{*}{$\begin{array}{l}\text { All cavities (main } \\
\text { analysis) } \\
\text { Cavities not in } \\
\text { atelectatic lung } \\
\text { Cavities in } \\
\text { atelectatic lung }\end{array}$} & 309 & 119 & 35 & 143 & 46 \\
\hline & & 262 & 108 & 41 & 121 & 42 \\
\hline & & 47 & 11 & 23 & 22 & 47 \\
\hline \multirow{3}{*}{$\begin{array}{l}0-12 \\
\text { months }\end{array}$} & \multirow{3}{*}{$\begin{array}{l}\text { All cavities (main } \\
\text { analysis) } \\
\text { Cavities not in } \\
\text { atelectatic lung } \\
\text { Cavities in } \\
\text { atelectatic lung }\end{array}$} & 295 & 148 & 40 & 101 & 37 \\
\hline & & 257 & 138 & 54 & 81 & 32 \\
\hline & & 38 & 10 & 26 & 20 & 53 \\
\hline
\end{tabular}

Considerable difficulty may arise in grading the severity of tuberculous lesions. In the East African trials the standard for a cavity-grading of "moderate" was a single cavity about $4 \mathrm{~cm}$. in size or two about $2 \mathrm{~cm}$. in size.

The severity of the lung lesions as a whole can be gauged partly by the cavity-grading just referred to, and partly by grading the anatomical extent of the disease itself. A scheme proposed by the W.H.O. (1960) has worked well in practice (Table III). A further refinement is to record the number of lung zones with abnormal shadows and whether the lesions are confined to one side or not. Such a system of grading will at least group the patients according to the type and extent of cavitation and the anatomical extent of the disease as a whole ; comparison can then be made between the response to treatment and the recurrence rate in the different groups.

TABLE III.-Grading of Anatomical Extent of Disease (W.H.O., 1960)

1. Trivial: that is, minimal lesions which the assessor regarded, purely on radio

graphic grounds, as inactive.
Slight: that is, minimal or rather larger lesions which he regarded as radiographically active.

Limited: that is, lesions of greater extent than in (2) but involving a total area of lung less than that occupied by the right upper lobe as visualized on a postero-

4. Moderate: that is, lesions of greater extent than in (3) but whose total extent, even if bilateral, did not exceed an area equivalent to the whole of one lung.
Extensive: that is, lesions which involved an area of more than the whole of on lung.

6. Gross: that is, very extensive bilateral disease.

\section{Value of Radiology in Bronchitis and Emphysema}

Let me now turn to the value of radiology in patients with cough, sputum, and dyspnoea due either to chronic bronchitis ar bronchitis complicated by emphysema or to emphysema and chronic bronchitis. I think it is still necessary to make a case for accuracy in the $x$-ray diagnosis of emphysema, since there seems to be considerable confusion about this. The accuracy of the $x$-ray diagnosis will be enhanced if the following criteria (Simon, 1964) are strictly adhered to.

1. An Excess of Air in the Lungs: The $x$-ray evidence for this is a low flat diaphragm and a large retrosternal translucent area.
2. Certain Cardiovascular Changes : A narrow vertical heart; a prominence of the pulmonary trunk; large hilar with small lungvessels.

3. Bullae : Avascular transradiant area which may be demarcated by a white line or may have no definite border.

If No. 1 and 2 are obvious the diagnosis can be made without No. 3 ; but if No. 2 is doubtful the diagnosis can still be made if No. 3 is well shown.

If these radiological criteria are strictly adhered to, then emphysema grade III-IV pan-acinar with air-trapping, widespread throughout both lungs, will usually be found (Reid and Millard, 1964). The dilated alveoli will be larger than $2 \mathrm{~mm}$. in diameter and the lungs will fail to deflate at necropsy, an indication of air-trapping. In addition, when the inflated lung is sliced the flimsy alveoli will retract below the level of the blood-vessels and airways. Conversely, emphysema of this type and degree will almost invariably cause changes in the radiograph, which will fulfil the criteria for its diagnosis.

Lesser degrees of emphysema, and emphysema without airtrapping, will usually cause no such changes, and will therefore not be detected.

Just as the accuracy of the clinical diagnosis of chronic bronchitis has been enhanced by the adoption of the form suggested by the M.R.C. (1960), so the accuracy of the $x$-ray diagnosis of emphysema will also be enhanced if the data are recorded on a suitable form such as the following:

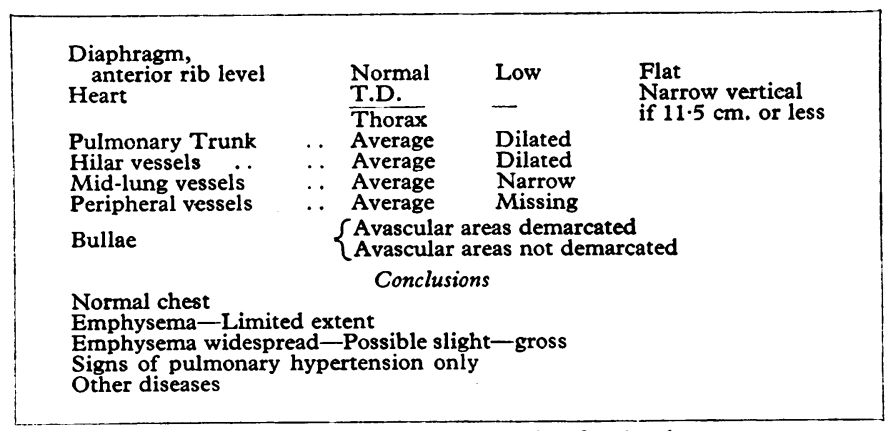

Showing Result of X-ray Examination for Emphysema

Recording of the facts in this manner will not only result in less error on re-reading or between different observers, but will enable any disagreement to be related to an agreed number of facts, and if the criteria are altered with increasing knowledge it will be possible to re-allocate the cases on the basis of the previously agreed facts. Thus errors of observation can be separated from errors of conclusion.

For the purposes of assessment, particularly in regard to prognosis, widespread general emphysema with air-trapping must be carefully distinguished from local avascular (bullous) areas, the rest of the lung being normal. These cases should be graded as local emphysema.

Occasionally there are several local bullae, and distinction from widespread emphysema may not then be easy, but is often unimportant. If in doubt the bias should be towards a diagnosis of widespread emphysema. This difficulty accounts for a few cases with apparently widespread disease but no dyspnoea, there still being sufficient normal lung left to prevent it.

\section{Emphysema Pattern}

Confusion has also arisen concerning the relation of the clinical diagnosis of dyspnoea to the pathological and radiological diagnosis. Practically all patients with the emphysema pattern in the radiographs were breathless on exercise and most of them were severely disabled by it. All showed evidence of airways obstruction with a low forced vital capacity, an F.E.V.1 below 1,200 ml., a peak flow rate below $2001 . / \mathrm{min}$., and a diffusion carbon monoxide below 10 (steady state). In another 
group of patients there was a similar degree of dyspnoea and respiratory-function-test impairment, but no emphysema pattern in the radiograph and either no emphysema or only pan-acinar emphysema grades I and II pathologically, or if there was any grade III it was only in a limited area of lung. These two groups, one with and one without the radiological emphysema pattern, should be kept separate when considering the prognosis of chronic bronchitis.

Another confusing factor is that in those with the radiological emphysema pattern further clinical deterioration in exercise tolerance usually occurs, but the radiograph often remains unchanged until the patient dies (of respiratory insufficiency). Once the respiratory reserves are used up, as a result of the alveolar disintegration, the additional loss of even a small quantity of lung tissue, too small to be detected in the radiograph, may cause a severe increase in the dyspnoea. Radiological deterioration is relatively uncommon.

It is apparent, therefore, that the radiograph has little value in the grading of emphysema, except to indicate that it is widespread and severe. Nor has the radiograph to date thrown much light on the onset of the condition. It is very uncommon, when a patient is first seen and the radiograph shows the " emphysema pattern," to obtain a previous normal radiograph.

The incidence of the emphysema pattern in the radiograph in a series of chronic bronchitics (Simon and Medvei, 1962) is shown in Table IV. A somewhat similar series of Dr. J. Batten (personal communication) gave similar results (Table V). Strange to say, nothing is known regarding which bronchitics get widespread emphysema, why it occurs, or even accurately when. Longer observation of chronic bronchitics and longer retention of their radiographs will no doubt enlighten us on these matters.

TABLB IV.-Chronic Bronchitis : 5-year Mortality (Simon and Medvei,

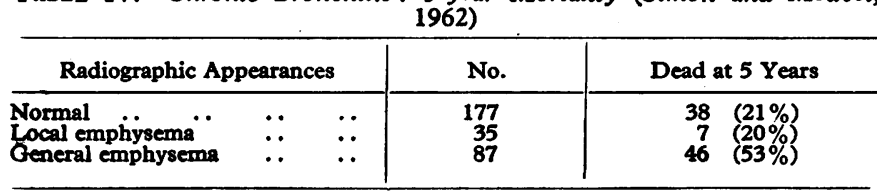

TABLB V.-Radiographic Classification of 112 Patients with Chronic Bronchitis (Dr. F. Batten's Series)

\begin{tabular}{|c|c|c|c|}
\hline & & No. of Patients & Age in Years \\
\hline $\begin{array}{l}\text { Tidespread emphysema .. } \\
\text { Possible slight emphysema } \\
\text { focalized emphysema } \quad . \\
\text { No emphysema .. }\end{array}$ & $\begin{array}{l}. \\
\because \\
\because\end{array}$ & $\begin{array}{l}24 \text { (22 males, } 2 \text { females) } \\
66 \\
15 \\
67 \text { ( } 49 \text { males, } 18 \text { females) }\end{array}$ & $\begin{array}{l}58.3(42-72) \\
55.4(24-72)\end{array}$ \\
\hline $\begin{array}{l}\text { Proportion of } 112 \text { chro } \\
\text { Simon and Gal } \\
\text { Simon and Mer } \\
\text { Fletcher et al. } \\
\text { Burrows et al. }\end{array}$ & & $\begin{array}{l}29 \% \text { of } 299 \text { chronic bro } \\
18 \% \text { of } 100 \text { chronic bro } \\
14 \% \text { of } 175 \text { chronic bro }\end{array}$ & $\begin{array}{l}\text { sema is } 21 \% \\
\text { hitics } \\
\text { hitics } \\
\text { hitics } \\
\text { hitics }\end{array}$ \\
\hline
\end{tabular}

The mortality of those with the emphysema pattern was $53 \%$ at five years, and preliminary results show that it was at least $70 \%$ at 10 years in Oswald and Medvei's series, which is much higher than when the radiograph is normal. Chronic bronchitics without a radiological emphysema pattern, either general or local, may be divided into those with a completely normal radiograph and those showing a normal diaphragm level and curve but large hilar vessels, and mid-lung vessels which are of roughly normal calibre and which extend out normally into the lung fields (see Fig.) - that is, there is neither vessel-narrowing nor appreciable vessel-loss. The heart shadow tends to be large, and often it increases in size at each incident of failure. There is evidence of airways obstruction and the diffusion carbon monoxide is also low, though often not as low as in those with the emphysema pattern, while the oxygen saturation tends to be low and the plasma $\mathrm{CO}_{2}$ high. A small proportion develop severe polycythaemia with a haemoglobin above $16 \mathrm{~g}$. and a packed cell volume of more than $55 \%$. Often several incidents of cardiac failure occur before one proves fatal. Post-mortem examination may show no emphysema (Simpson,
Heard, and Laws, 1963), or it may be no more than pan-acinar grade I-II (Reid and Millard, 1964). In some cases there may be centri-acinar emphysema (? without air-trapping), but the relation of this to the condition is unknown. Right ventricular hypertrophy is often marked.

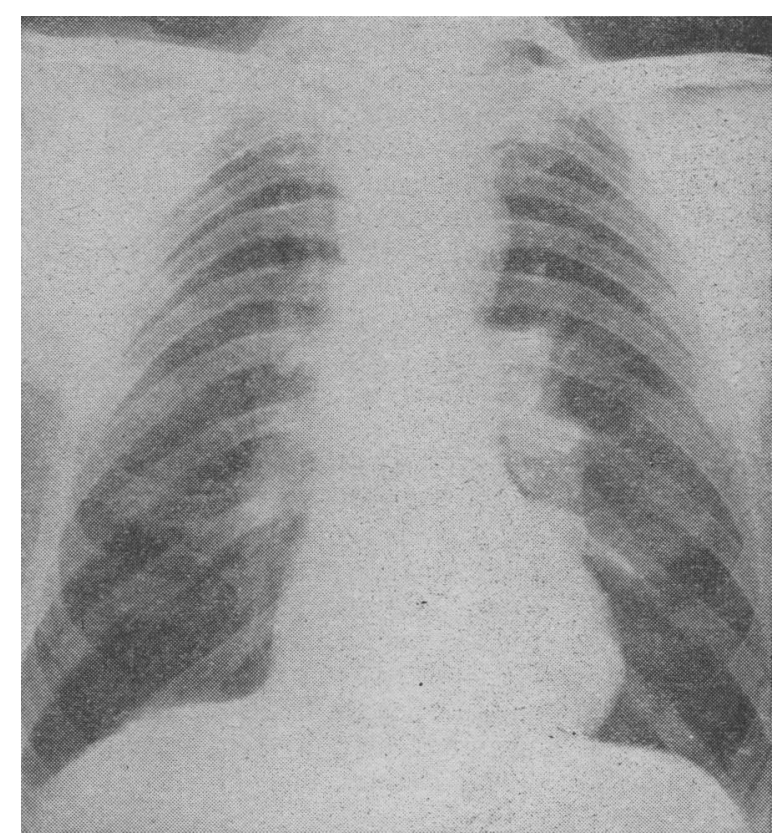

Radiograph showing the condition in a man aged 55 with cough, mucoid sputum, and increasing dyspnoea. Normal diaphragm, larger hilar, but normal lung vessels. Post-mortem pan-acinar emphysema grade I only. Large pulmonary arteries and right ventricular hypertrophy.

This group with the large hilar but normal lung vessels and diaphragm can now be defined clinically and radiologically, and is therefore a suitable field for epidemiological study. As yet the incidence of this complication among chronic bronchitics is not accurately known, nor is the prognosis at 5-10 years, though studies of individual cases suggest it is poor, but perhaps better than in those showing an emphysema pattern.

\section{Right Ventricular Hypertrophy}

The incidence of right ventricular hypertrophy in chronic bronchitics can be studied by means of the E.C.G. in the living patient with more assurance since the work of Millard (1965). By measuring ventricular weight instead of thickness by the method of Fulton et al. (1952) a more accurate assessment of hypertrophy was possible and therefore criteria for interpretation of the E.C.G. tracings in these cases.

The incidence of right ventricular hypertrophy from the E.C.G. tracings in Dr. John Batten's series of chronic bronchitics is shown in Table VI (Batten and Chappell, personal communication). These rather preliminary figures raise a suspicion that if you divide the bronchitics in an outpatient clinic into those with a peak expiratory flow rate above 1501 ./ min. and those below it is the latter group who develop E.C.G. evidence of right ventricular hypertrophy, and who will become

TABLE VI.-Incidence of Right Ventricular Hypertrophy

\begin{tabular}{|c|c|c|c|}
\hline & $\begin{array}{l}\text { No. of } \\
\text { Patients }\end{array}$ & $\begin{array}{c}\text { Right } \\
\text { Ventricular } \\
\text { Hypertrophy } \\
\text { (Millard) }\end{array}$ & P. pubmonale \\
\hline $\begin{array}{l}\text { Widespread emphysema } \\
\text { Slight, localized, or no emphysema } \\
\text { (PF <200 1./min. and F.E.V.1< } \\
\text { 1,200 ml.) } \\
\text { Slight, localized, or no emphysema } \\
\text { (PF }>200 \text { l./min. F.E.V.1 }>1,200 \\
\text { ml.) } . . \quad \text {.. } \quad . . \quad . .\end{array}$ & $\begin{array}{l}24 \\
43\end{array}$ & $\begin{array}{ll}4 & (17 \%) \\
7 & (16 \%) \\
0 & \end{array}$ & $\begin{array}{l}6(25 \%) \\
5(12 \%) \\
-\end{array}$ \\
\hline
\end{tabular}


blue and bloated, as described by Dornhorst (1955) and Scadding (1963). The incidence of right ventricular hypertrophy in those with the radiological emphysema pattern is seen to be about the same at $17 \%$, but in cases where a postmortem examination has been made the degree of hypertrophy was relatively slight and less marked than in those chronic bronchitics with the large hilar but normal lung vessels.

The incidence of widespread emphysema can be studied in conditions other than chronic bronchitis, particularly in cases of possible industrial pulmonary disease. A review of 400 cadmiumworkers failed to show a significant number with the emphysema pattern, though some had respiratory function studies indicating airways obstruction (Bonnell, 1955). A review of 400 coalminers seeking compensation was studied by Caplan et al. (1966); here the incidence of the radiographic emphysema pattern was small, but was higher in those with the lower categories of nodulation. This suggests that the focal emphysema of coal-miners does not give rise to widespread emphysema with air-trapping, and accounts for the difficulty found in trying to correlate the nodular shadows with disability.

Finally, there are other spheres in which radiology can be of value in epidemiological surveys, such as the incidence of hiatus hernia or of rheumatoid arthritis. In this last context it is worth noting that the percentage of $x$-ray-positive cases showing clinical manifestations of this disease will be increased from $75 \%$ to $91 \%$ if the metatarsal heads are radiographed as well as the hands and wrists, even if there are no symptoms referable to the feet (Thould and Simon, 1966).

\section{Summary and Conclusions}

There is a definite place for radiology in trials of drugs in the treatment of pulmonary tuberculosis and in some epidemio- logical surveys, particularly in coal-miners and certain other workers in industry. It is also of value in surveys of patients with chronic bronchitis, for patients showing an emphysema pattern have a much worse prognosis than those whose chest radiograph is normal. Another group with large hilar but no narrowing of the mid-lung vessels is also a suitable one for study.

\section{REFERENCES}

Bonnell, J. A. (1955). Brit. F. industr. Med., 12, 181.

Burrows, B., Niden, A. H., Barclay, W. R., and Kasick, J. E. (1965). Am. Rev. Resp. Dis., 91, 521.

Caplan, A. (1962). Ibid., 19, 171.

Reid, L., and Simon, G. (1966). Clin. Radiol. In press.

Dornhorst, A.' C. (1955). Lancet, 1, 1185.

Eade, A. W. T., Harrison, G. K., Large, S. E., Mackay-Dick, J., Reid, L., and Riddell, R. W. (1959). Thorax, 14, 104.

Fletcher, C. M. (1964). Meth. Inform. Med., 3, 98. Jones, N. L., Burrows, B., and Niden, A. H. (1964). Am. Rev. Resp. Dis., $90,1$.

Fulton, R. M., Hutchinson, E. C., and Jones, A. M. (1952). Brit. Heart f., 14, 413 .

Garland, L. H. (1950). Amer. 7. Roentgenol., 64, 32.

Medical Research Council (1960). Short Questionary on Respiratory Symptoms.

(1965). Lancet, 1, 775.

Millard, J. (1965). M.D. thesis. Univ. London.

Reid, L., and Millard, F. J. C. (1964). Clin. Radiol., 15, 307.

Rivers, D., Wise, M. E., King, E. J., and Nagelschmidt, G. (1960). Brit. f. industr. Med., 17, 87.

Scadding, J. G. (1963). Brit. med. F., 2, 1425.

Simon, G. (1964). Clin. Radiol., 15, 293.

- and Galbraith, H.-J. B. (1953). Lancet, 2, 850. and Medvei, V. C. (1962). Thorax, 17, 5.

Simpson, T., Heard, B., and Laws, J. W. (1963). Thorax, 18, 361.

Thould, A. K., and Simon, G. (1966). Ann. rheum. Dis. In press.

W.H.O. (1960). Bull. Wld Hith Org., 23, 543.

Veterans Administration (1958). Transactions of 17th Conference of the Veterans Administration on the Chemotherapy of Tuberculosis, p. 481.

Yerushalmy, J., Garland, L. H., Harkness, J. T., Hinshaw, H. C., Miller, E. R., Shipman, S. J., and Zwerling, H. B. (1951). Amer. Rev. Tuberc., 64, 225.

\title{
Cough Seizures in Patients with Cerebral Lesions
}

\author{
J. A. MORGAN-HUGHES,* B.A., M.D., B.CHIR., M.R.C.P.
}

Brit. med. Ғ., 1966, 2, 494-494

Since the observations of Charcot (1876) it has been recognized that prolonged coughing may sometimes be associated with a transient disturbance of cerebral function. Two cases were originally described, one patient experiencing brief vertiginous episodes, and the other unconsciousness with clonic movements of the face and arm. Charcot concluded that the attacks were due to irritation of the laryngeal nerves, a theory which was accepted in a modified form by many subsequent writers (Krishaber, 1882 ; Getchell, 1896).

McBride (1884) was the first to suggest that the symptoms were caused by cerebral anoxia. He believed that the increase in intrathoracic pressure produced during a paroxysm of coughing hindered the return of venous blood to the heart, thereby causing a fall in cardiac output. Little attention was paid to this idea, however, until Wilkins and Friedland (1944) recorded a diminution in the venous return and cardiac output of healthy subjects when performing the Valsalva manœuvre.

Sharpey-Schafer (1953a, 1953b) elegantly demonstrated the haemodynamic effects of prolonged coughing. With the use of capacitance manometers, he recorded intrathoracic, intracardiac, venous, and arterial pressures in 40 healthy subjects

* Institute of Neurology, Queen Square, London. and in 27 patients with a history of cough syncope. There was no qualitative difference between the effects of coughing in the two groups, the circulatory changes being proportional to the violence of the cough. Both continuous and intermittent coughing were accompanied by a sudden increase in intrathoracic pressure followed by a fall in systemic arterial pressure, unconsciousness usually occurring during the period of hypotension observed at the end of the paroxysm.

It has often been suggested, however, that other factors may be equally important in the production of cough seizures. Baker (1949) spoke of a "cerebral susceptibility," and O'Doherty (1953), who described five cases with electroencephalographic changes, concluded that an "inherent abnormality of cortical function" must contribute to this syndrome.

The four cases described below lend support to the view that disorders of the brain and cerebral vessels may occasionally be important aetiological factors.

\section{Case 1 (No. 47288)}

A housewife aged 60 was admitted to the National Hospital under the care of Sir Charles Symonds in September 1953 with a 